\title{
Prediction of steel resistance to stress corrosion cracking in seawater based on accelerated tests and structural studies
}

\author{
Svetlana Mushnikova*, Oleg Kharkov \\ NRC "Kurchatov Institute" - CRISM "Prometey", 191015 St. Petersburg, 49 Shpalernaya str., Russia
}

\begin{abstract}
The paper presents the tests results of resistance of various structural steel classes to SCC in chloride solutions. The experiments were performed using cantilever bending tests developed by NRC "Kurchatov Institute" - CRISM "Prometey" with stepwise increasing load of Charpy-type precracking specimens. The criterion estimation of resistance to SCC when $\beta=\sigma_{\mathrm{SCC}} / \sigma_{\mathrm{C}}>0.85$ was confirmed by the laboratory test results compared with the case studies of corrosion-mechanical fracture of shipbuilding structures in real life service conditions. A new approach of SCC susceptibility of austenitic stainless steels in marine conditions is proposed. It is based on estimation of the critical temperature of SCC when testing for SSRT in a concentrated solution of calcium chloride at temperatures from $20^{\circ} \mathrm{C}$ to $100^{\circ} \mathrm{C}$. Specific features of the structural-phase composition of steels that detrimentally affect the resistance to SCC were discovered during the complex testing.
\end{abstract}

\section{Introduction}

In recent years, austenitic stainless steels, hardened through the use of various methods of thermal and thermo-deformational treatments, are beginning to be used in shipbuilding together with low- and mediumalloyed steels. Common methods of hardening stainless steels are: solid-solution hardening (the elements that form the interstitial and substitutional solid solutions); dislocation hardening due to cold plastic deformation; dispersion hardening during the formation of particles of carbide, nitride or intermetallic phases from a supersaturated $\gamma$-solid solution (during isothermal aging); grain boundary hardening; substructural hardening during high-temperature thermomechanical processing (HTMP) [1-4]. Among high-strength austenitic steels, nitrogen-containing steels have the greatest potential due to the unique ability of nitrogen not only to participate, but also to play a leading role in all hardening mechanisms [5-9].

At the same time, in order to successfully introduce high-strength steels of any structural classes for the manufacture of high-loaded marine structures, it is necessary to determine their resistance to stress corrosion cracking (SCC). Stress corrosion cracking remains one of the most dangerous fracture types of medium and high alloy steels in seawater, despite significant achievements in identifying and explaining the nature of SCC [10-13]. An adequate evaluation of susceptibility to SCC depends on development of effective test methods that simulate critical maintenance conditions and include various types of loading schemes.

At present, dynamic test methods are widely used to estimate the resistance to SCC, in which samples are continuously or discretely loaded in an aggressive environment. In this work, the results of comparative studies of resistance to SCC of low- and medium-alloyed steels and austenitic stainless steels, which were prepared with application of various strengthening mechanisms, are given.

\section{Materials and methods of investigations}

The object of the study was low- and medium-alloyed shipbuilding steels of different classes with yield strength of 370-1200 MPa with ferritic-bainite, bainitemartensitic and martensitic structure.

The second group of materials under study was $0.04 \% \mathrm{C}-20 \% \mathrm{Cr}-6 \% \mathrm{Ni}-11 \% \mathrm{Mn}-1.5 \% \mathrm{Mo}-0.47 \% \mathrm{~N}-\mathrm{V}-\mathrm{Nb}$ austenitic stainless steel produced by various methods of hardening and differing in structural phase composition:

- $\quad$ steel with yield strength $\sigma_{0.2}=400-600 \mathrm{MPa}$, having a recrystallized $\gamma$-structure after austenitization, as well as from $30 \%$ to $0 \% \delta$-ferrite due to the variation of nitrogen concentration from 0.01 to $0.50 \%$ (mass.);

- $\quad$ sensitized steel during aging at $700^{\circ} \mathrm{C}$ for 2 and 10 hours having yield strength $\sigma_{0.2}=550-780 \mathrm{MPa}$; steel has a high density of grain boundary carbides and nitrides due to double carbon content $(0.09 \%)$ compared to the required;

- steel resulting from HTMP and having yield strength $\sigma_{0.2}=600-980 \mathrm{MPa}$;

- cold hardening steel with a deformation structure and $\sigma_{0.2}=1000-1330 \mathrm{MPa}$, obtained during cold rolling with degree of plastic deformation $15-47 \%$.

The structure, phase composition of steels was

* Corresponding author: npk3@crism.ru 
studied by the following methods:

- metallographic analysis was performed using an AxioObserver (Zeiss) light inverted metallographic microscope,

- electron microstructural studies were performed on a Tecnai G2 30 S-TWIN transmission microscope with an accelerating voltage of $200 \mathrm{kV}$,

- fractographic studies were performed on Quanta 200 scanning electron microscopes with the PEGASUS, Philips SEM-535 and Stereoscan-150 systems at an accelerating voltage of $15 \mathrm{kV}$.

Steel resistance to SCC was determined by slow strain rate tests (SSRT) and by cantilever bending of precracking specimens. SSRT is designed to detect the initiation of stress corrosion cracks. Already existing crack can be propagated by using the method of cantilever bending, based on the application of principles of linear elastic fracture mechanics.

SSRT were carried out according to standards ISO 7539-7 and ASTM G129 [14,15] under some conditions:

- the rate of deformation was $2 \cdot 10^{-7} \mathrm{~s}^{-1}$ (for stainless steels) and $2 \cdot 10^{-6} \mathrm{~s}^{-1}$ (low- and medium-alloyed steels);

- used smooth cylindrical specimens;

- tested in air to characterize the material and to use it as reference;

- tested in $3.5 \% \mathrm{NaCl}$ at a free corrosion potential and at room temperature;

- tested in $25 \% \mathrm{CaCl}_{2}$ at temperatures $20-100^{\circ} \mathrm{C}$.

When tested by SSRT elongation and reduction of area were measured on broken specimens. Values $\delta$ and $\psi$ obtained in a corrosive environment were compared with same characteristics obtained in air.

An original technique has been developed for testing with cantilever bending. According to the method, prismatic Charpy-type precracked specimens (with a machined notch and a fatigue crack) were periodically (stepwise) loaded on a special installation. The cantilever bending of precracking specimens were carried out at room temperature in the same corrosive media. Tests were conducted on a time base of 720 hours. After the breakdown of specimens the crack length was determined and the failure stress $\left(\sigma_{\mathrm{SCC}}\right.$ or $\left.\sigma_{\mathrm{C}}\right)$ was calculated according to the requirements of ASTM E1681 and ISO 7539-9:2003 [16, 17]. A quantitative assessment of resistance to SCC was to calculate the ratio of breaking stresses in a corrosive environment to air $\left(\beta=\sigma_{\mathrm{SCC}} / \sigma_{\mathrm{C}}\right)$

\section{The results of experimental studies and their discussion}

\subsection{Test results of low and medium alloyed steels}

Figure 1 presents the test results of low and medium alloyed steels obtained with the periodically increasing load in the form of a generalized dependence $\ll \sigma_{0,2}-$ $\beta=\sigma_{S C C} / \sigma_{C} »$. Comparison of accelerated laboratory tests results for steels that have shown susceptibility to SCC (fig. 1) with incidents of steel damage because of generation corrosion cracks in real life service conditions of shipbuilding structures in natural sea water, allowed us to determine the threshold value of parameter $\beta>0.85$.

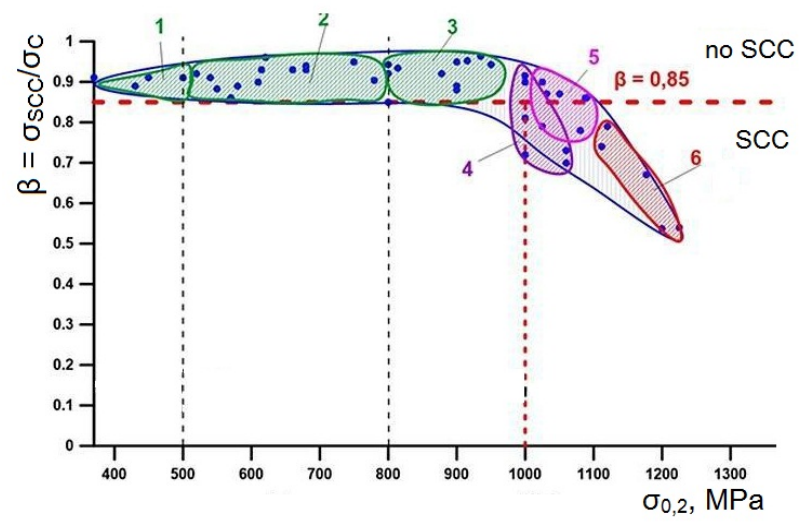

Fig. 1 - Influence of yield strength of low and medium alloyed steels on the characteristic of resistance to SCC $\beta$ when tested by the method of stepped cantilever bending in $3.5 \% \mathrm{NaCl}$ :

1- ferritic-bainitic low alloy steels,

2- bainitic-martensitic medium-alloyed steels;

3, 6- martensitic alloyed steels;

4- low carbon martensitic steels;

5- medium carbon martensitic steels

In addition, the same criterion $\beta$ value was obtained as a result of long (up to 10 thousand hours) tests of cantilever bending under constant load in seawater (fig. 2 ). The value $\beta=0.85$ corresponded to the moment of the beginning of the decrease in the $\mathrm{K}_{\mathrm{QSCC}}$ value.

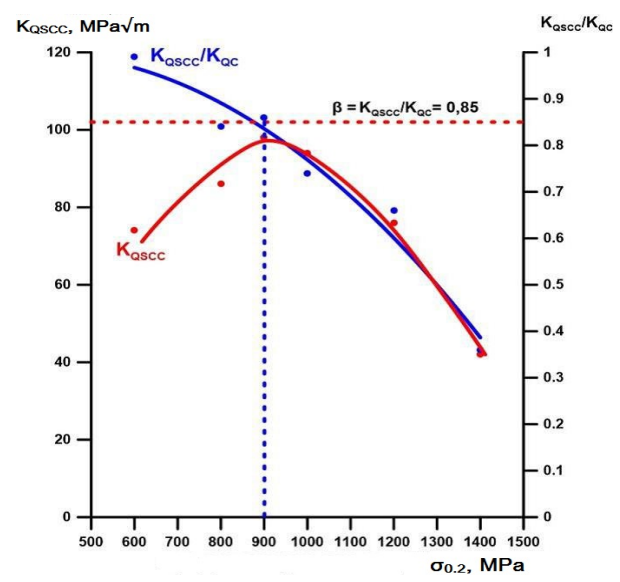

Fig. 2 - Influence of yield strength of shipbuilding steels on threshold stress intensity factor $\left(\mathrm{K}_{\mathrm{QSCC}}\right)$ when tested by the method of cantilever bending under constant load

in sea water and relative ratio $\left(\mathrm{K}_{\mathrm{QSCC}} / \mathrm{K}_{\mathrm{QC}}\right)[18]$

The studied low and medium alloyed steels were conditionally divided according to the strength levels into 6 areas, each of which corresponds to a certain structural-phase composition of the steel.

It was found (fig. 1) those low- and medium-alloyed steels with ferritic-bainitic, bainitic-martensitic and martensitic structures and yield strengths from 370 to $1000 \mathrm{MPa}$ are resistant to $\mathrm{SCC}$ in $3.5 \% \mathrm{NaCl}$ at a free corrosion potential. In low-carbon medium-alloyed steels 
with the structure of the lath martensite, SCC is observed at a value of the yield strength above $1000 \mathrm{MPa}$ (Fig. 1, sector 4). A significant effect on the appearance of the SCC has a dislocation density. At density of dislocations $\rho \geq 4 \cdot 10^{14} \mathrm{~m}^{-2}$ low-carbon medium-alloyed steels with yield strength over $1000 \mathrm{MPa}$ are subjected to SCC in $3.5 \% \mathrm{NaCl}$. Other factors of the structural state of martensitic steels have almost no effect on SCC.

Medium carbon steels with a needle martensite structure begin to undergo SCC when $\sigma_{0.2}>1050 \mathrm{MPa}$ (Fig. 1, sector 5). Fractographic studies have shown that the character of fractures of specimens undergo to SCC depends on the level of strength: at $\sigma_{0.2}=1050-1080 \mathrm{MPa}$, breakdown occurs predominantly with a transcrystalline quasi-cleaved, and at $\sigma_{0.2} \sim 1200 \mathrm{MPa}$, brittle grainboundary fracture with the formation of spillages.

Tests of smooth specimens under slow strain (SSRT) did not detect the sensibility of high-strength mediumalloyed steels to $\mathrm{SCC}$ in $3.5 \% \mathrm{NaCl}$ at free corrosion potential unlike cantilever bending with stepwise increasing load (Fig. 3). This is obtained despite the identical time base of tests ( 720 hours) and the similar nature of (stepwise or continuous) deformation.

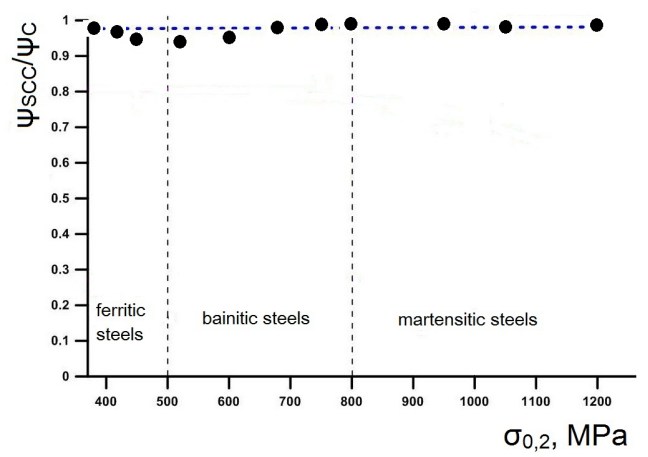

Fig. 3 - Influence of yield strength of low and medium alloyed steels on the characteristic of resistance to SCC

$\psi_{\mathrm{SCC}} / \psi_{\mathrm{C}}$ when tested by SSRT in $3.5 \% \mathrm{NaCl}$

3.2 Test results of nitrogen-containing austenitic stainless steel produced by various methods of hardening and differing in structural phase composition

\subsubsection{Tests in $3.5 \% \mathrm{NaCl}$ at room temperature}

The resistance to SCC of samples of nitrogen-containing steel of basic composition $0.04 \% \mathrm{C}-20 \% \mathrm{Cr}-6 \% \mathrm{Ni}-$ $11 \% \mathrm{Mn}-1.5 \% \mathrm{Mo}-0.47 \% \mathrm{~N}-\mathrm{V}-\mathrm{Nb}$ was studied in $3.5 \%$ $\mathrm{NaCl}$ at room temperature using two methods. Generalized SSRT-test results for steels manufactured using various technologies are presented in fig. 4. All investigated variants of nitrogen-containing steel with the exception of sensitized steel retain resistance to SCC up to $\sigma_{0.2}=1330 \mathrm{MPa}$ (fig. 4) [19-21].

The same dependence, showing the absence of nonsensitized steels to SCC, was also obtained when tested by the method of stepped cantilever bending. Data obtained is in contrast to medium-alloyed steels with a well-defined dependence of susceptibility to SCC on the strength level (fig. 1).

A comparison of susceptibility to $\operatorname{SCC}\left(\beta=\sigma_{\mathrm{SCC}} / \sigma_{\mathrm{C}}\right.$, $\psi_{\mathrm{SCC}} / \psi_{\mathrm{C}}$ and $\left.\delta_{\mathrm{SCC}} / \delta_{\mathrm{C}}\right)$, obtained by aged sensitized steel testing, with the values of toughness, shows the existence of a correlation (fig. 5). In addition, it follows that SSRT method is the most effective (values $\psi_{\mathrm{SCC}} / \psi_{\mathrm{C}}$ and $\delta_{\mathrm{SCC}} / \delta_{\mathrm{C}}$ are much reduced).

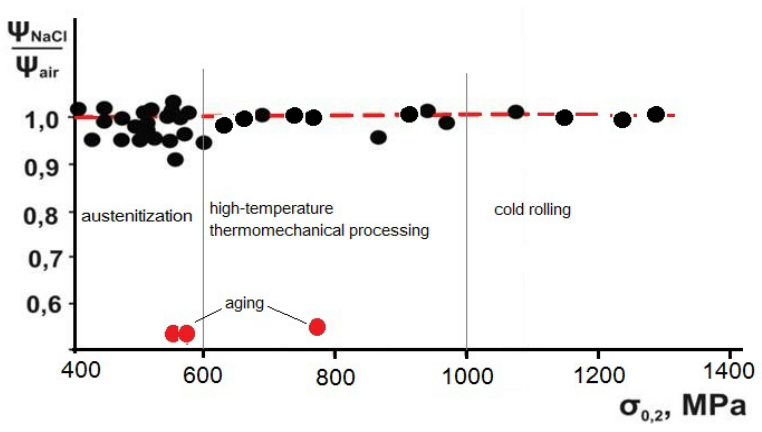

Fig. 4 - Influence of yield strength of nitrogencontaining austenitic stainless steel produced by various methods of hardening on the characteristic of resistance to $\mathrm{SCC} \psi_{\mathrm{SCC}} / \psi_{\mathrm{C}}$ when tested by SSRT in $3.5 \% \mathrm{NaCl}$.

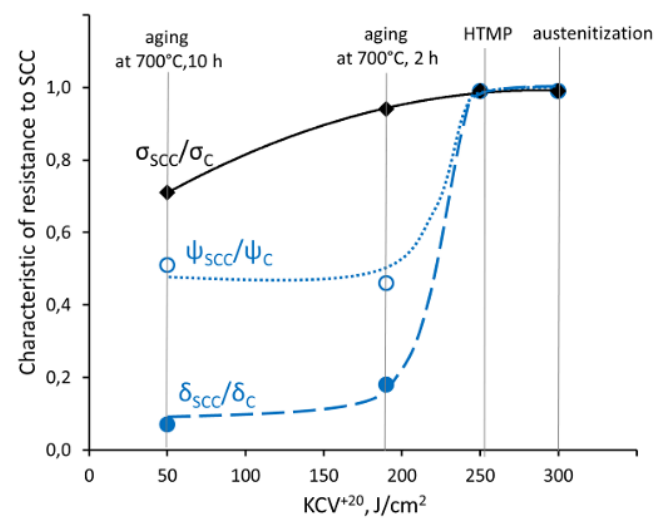

Fig. 5 - Influence of sensitized high-carbon stainless steel toughness on susceptibility to SCC in $3.5 \% \mathrm{NaCl}$ when tested by the SSRT method $\left(\psi_{\mathrm{SCC}} / \psi_{\mathrm{C}}\right.$ and $\left.\delta_{\mathrm{SCC}} / \delta_{\mathrm{C}}\right)$ and stepped cantilever bend $\left(\beta=\sigma_{\mathrm{SCC}} / \sigma_{\mathrm{C}}\right)$

The lower sensitivity of cantilever bending method for austenitic stainless steels (Fig. 5) may be associated with the complicate trajectory of slow growth of the corrosion crack along the winding boundaries of austenite grains (Fig. 6) [19].

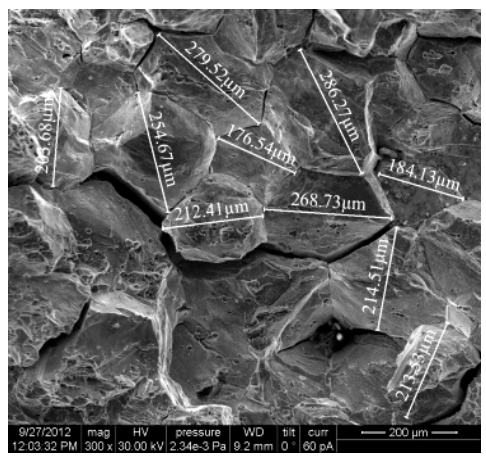

Fig. 6 - Fracture of sensitized austenitic stainless steel tested in $3.5 \% \mathrm{NaCl}$ 


\subsubsection{Tests in in $25 \% \mathrm{CaCl}_{2}$ at elevated temperatures}

For the ranking of non-sensitized nitrogen-containing steels in order to intensify the process of SCC, tests were conducted by SSRT in $25 \% \mathrm{CaCl}_{2}$ at elevated temperatures.

It is shown that at the test temperatures of 20 and $50^{\circ} \mathrm{C}$, regardless of the amount of the ferritic phase, the steel is resistant to SCC (Fig. 7). At test temperatures 70 and $90^{\circ} \mathrm{C}$ as the amount of $\delta$-ferrite increases and the nitrogen content decreases, the SCC susceptibility characteristics decrease.

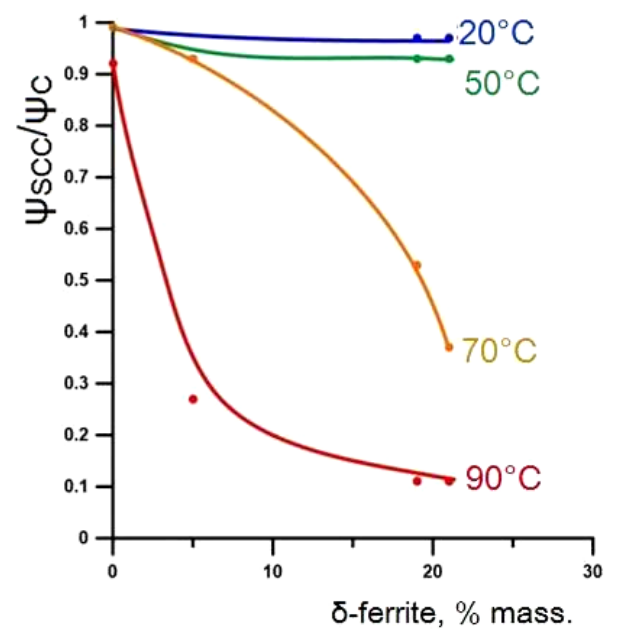

Fig. 7 - Influence of the content of $\delta$-ferrite in nitrogencontaining austenitic stainless steel on the resistance to SCC when tested by SSRT in $25 \% \mathrm{CaCl}_{2}$ at elevated temperatures

Metallographic analysis shows that corrosion cracks grow from pits predominantly transcrystalline in the austenitic phase, bending around ferritic grains (Fig. 8).

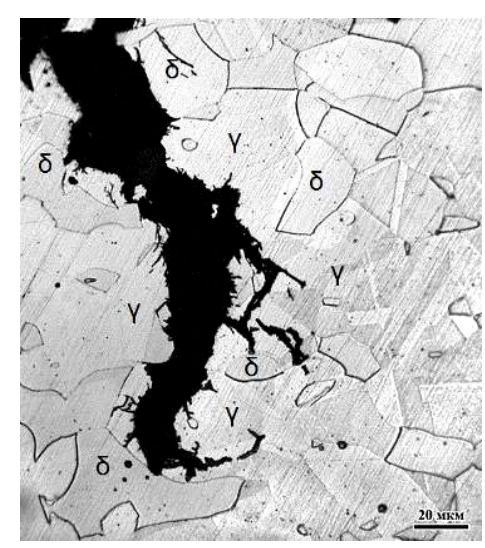

Fig. 8 - The growth of corrosion cracks in nitrogencontaining steel with $\delta$-ferrite by SSRT in $25 \% \mathrm{CaCl}_{2}$ at elevated temperatures

The nature of crack growth was explained by the repartition of alloying elements $(\mathrm{Cr}, \mathrm{Mo}, \mathrm{N})$ between the phases of austenite and $\delta$-ferrite. As a result, the PRE values have changed (Fig. 9).

Figure 7 shows that low-strength nitrogen-containing steel steel with a fully austenitic structure, obtained as a result of high-temperature quenching in water is resistant to SCC over the entire range of temperatures studied, including $90^{\circ} \mathrm{C}$.

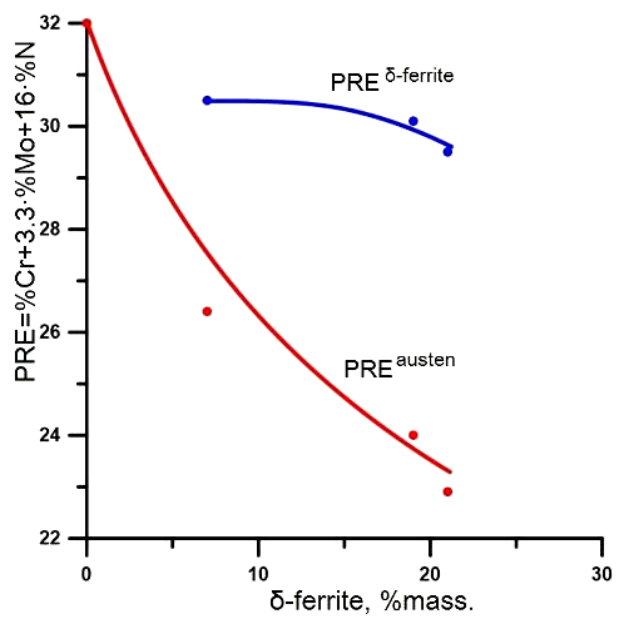

Fig. 9 - Influence of the content of $\delta$-ferrite in nitrogencontaining austenitic stainless steel on phase resistance to pitting corrosion $(\mathrm{PRE}=\% \mathrm{Cr}+3.3 \cdot \% \mathrm{Mo}+16 \cdot \% \mathrm{~N})$

High-strength steel obtained by high-temperature thermomechanical treatment (HTMP) is not yet sensitive to $\mathrm{SCC}$ at $70^{\circ} \mathrm{C}$, but it brittle breaks down at $90^{\circ} \mathrm{C}$ (Fig. 10). In the aged sensitized state the steel is not resistant at room temperature. SCC resistance of nitrogencontaining austenitic stainless steel strengthened during cold rolling decreases monotonously (Fig. 10).

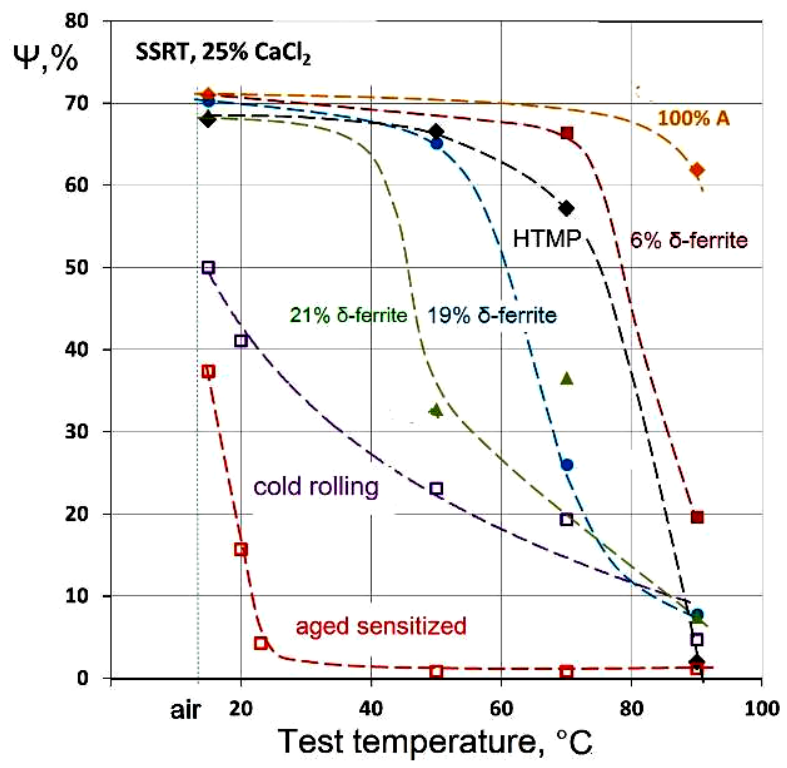

Fig. 10 - The dependences of the values of the relative narrowing $\psi$ on the test temperature in $25 \% \mathrm{CaCl}_{2}$ (SSRT) with various methods of nitrogen-containing steel hardening

Analysis of the test results of the investigated variants of nitrogen-containing steel made it possible to assess the SCC resistance as a parameter of the critical temperature for corrosion cracking $\mathrm{T}_{\text {cr }} \mathrm{SCC}$, as the minimum test temperature at which SCC is observed. 


\section{Conclusion}

1. The most effective estimate of the susceptibility to SCC of low- and medium-alloyed steels in 3.5\% $\mathrm{NaCl}$ with the potential for free corrosion is the method of cantilever bending with a stepwise increasing load of precracking specimens. The criterion estimation of resistance to SCC when $\beta=\sigma_{\mathrm{SCC}} / \sigma_{\mathrm{C}}>0.85$ was confirmed by the laboratory test results compared with the case studies of corrosionmechanical fracture of shipbuilding structures in real life service conditions.

2. To predict SCC resistance of austenitic steels in the marine conditions, the SSRT method is recommended as the main test method.

3. A new approach of SCC susceptibility of austenitic stainless steels in marine conditions is proposed. It is based on estimation of the critical temperature of SCC when testing for SSRT in a concentrated solution of calcium chloride at temperatures from $20^{\circ} \mathrm{C}$ to $100^{\circ} \mathrm{C}$.

4. The presence in nitrogen-containing austenitic steel up to $30 \%$ of $\delta$-ferrite or structure obtained at HTMP does not cause sensitivity to $\mathrm{SCC}$ in $25 \% \mathrm{CaCl}_{2}$ at temperature including $50^{\circ} \mathrm{C}$.

5. The deformation structure (without martensitic transformation) obtained during cold plastic deformation (with a degree up to $47 \%$ ) and especially the state sensitized during aging reduce the critical temperature of SCC.

\section{References}

1. V.V. Sagaradze, A.I. Uvarov, Hardening and Properties of Austenitic Steels (Yekaterinburg: UrO, Ross. Akad. Nauk, 2013)

2. O.A. Bannykh, V.M. Blinov, Age-Hardenable NonMagnetic Vanadium-Containing Steels (Moscow: Nauka, 1980)

3. Y. Ikegami, R. Nemoto , ISIJ Intern. 36, 7, 855 (1996)

4. L.P. Karjalainen, T. Taulavuori M. Sellman, A. Kyröläinen, Steel Research Int. 79, 6, 404 (2008)

5. H.J.C. Speidel, M.O. Speidel, HNS-2003 (Institute of Metallurgy ETH. Zurich, 2003)

6. M.V. Pridantsev, N.P. Talov, , D.L. Levin, HighStrength Austenitic Steel (Moscow: Metallurgiya, 1969)

7. V.G. Gavriljuk, H. Berns High Nitrogen Steels: Structure, Properties, Manufacture, Applications (Springer - Verlag Berlin Heidelberg, 1999)

8. G. Balachandran, Developments in the Manufacture of High Nitrogen Stainless (Alpha Science International Ltd., Pangbourne, UK; Copiraight Narosa Publishing House, New Delhi, 2004)

9. R. Ritzenhoff, A. Hahn Corrosion resistance of high nitrogen steels (ch. 3. InTech, Shanghai, China, 2012)
10. Metals Handbook (Ninth Edition, V. 13, Corrosion, Ed. L.J. Korb, D.L. Olson, USA: ASM International, 1994)

11. K.H. Lo, C.H. Shek, J.K.L. Lai, Mater. Sci. and Eng., 65, 39 (2009)

12. T. Prosek, A. Iversen, C. Taxen, D. Thierry, Corrosion. 65, 2, 105 (2009)

13. J. Heselmans P. Vermeij, Corrosion/2013 paper number 2331, NACE International, Houston, Texas (2013)

14. ISO 7539-7:2005 Corrosion of metals and alloys Stress corrosion testing - Part 7: Method for slow strain rate testing

15. ASTM G 129 Standard Practice for Slow Strain Rate Testing to Evaluate the Susceptibility of Metallic Materials to Environmentally Assisted Cracking

16. ASTM E1681 Standard Test Method for Determining Threshold Stress Intensity Factor for Environment-Assisted Cracking of Metallic Materials

17. ISO 7539-9:2003 Corrosion of metals and alloys Stress corrosion testing - Part 9: Preparation and use of pre-cracked specimens for tests under rising load or rising displacement

18. A.S. Oryshchenko, S.Yu. Mushnikova, A.A. Kharkov, G.Yu. Kalinin, Proc. Eur. Corrosion Congr. EUROCORR'2010, Moscow (2010)

19. Yu.I. Filippov, V.V. Sagaradze, V.A. Zavalishin, N.L. Pecherkina, N.V. Kataeva, S.Yu. Mushnikova, S.K. Kostin, G.Yu. Kalinin, Phys. of Met. and Metallogr. 115, 586 (2014)

20. S.Yu. Mushnikova, V.V. Sagaradze, Yu.I. Filippov, N.V. Kataeva, V.A. Zavalishin, V.A. Malyshevskii, G.Yu. Kalinin, S.K. Kostin Phys. of Met. and Metallogr. 116, 626 (2015)

21. S.Yu. Mushnikova, S.K. Kostin, V.V. Sagaradze, N.V. Kataeva, Phys. of Met. and Metall. 118, 11, 1223 (2017) 